basis, the good conductivity axis would be normal to the molecular plane, while the intermediate and low conductivity axes would be in this plane with the molecules aligned at angles of approximately $\pm 73^{\circ}$ and $\pm 17^{\circ}$ to the respective conductivity axes.

- The work, which is being continued, forms part of the research programme of the National Physical Laboratory and the above account is published by permission of the Director of the Laboratory.

Physics Division,

R. W. POWELI

National Physical Laboratory,

Teddington, Middlesex. July 17.

' Powell, R. W., Nature, 164, 153 (1949).

2 Bradley, A. J., Z. Kristall., 91, 302 (1935).

"Laves, F., Z. Kristall., 84, 293 (1933).

\section{Combustion of Fuel Droplets}

WE were very much interested in Mr. G. A. E. Godsave's letter ${ }^{1}$ on the combustion of fuel droplets, for we also have been studying the same subject.

We have measured the time of burning of droplets suspended at the end of a silica filament or metallic wire by a photographic method in still air. The time of burning, $T$, is found to be directly proportional to the square of the initial diameter of the droplet, $d_{0}$, over the range of drop-size investigated (approximately $1.3-0.3 \mathrm{~mm}$.). This is exactly the same as saying that the burning-rate is directly proportional to the diameter, $d$, of the drop at any instant, which is the result obtained in Godsave's experiment.

We can compare the life of droplets of various kinds of fuel by means of the relation $T / d_{0}{ }^{2}$ (which we call the specific burning-time). When using the platinum wire in our experiment, it was found that the burning-time was considerably shortened. This may be due to catalytic combustion.

We propose to give a detailed account of our work in the Transactions of the Society of Mechanical Engineers, Japan.

\section{Seitichiro KumagaI \\ Hiroshx IsOdA}

Department of Mechanical Engineering, Faculty of Engineering, University, Tokyo.

Aug. 25.

${ }^{1}$ Nature, 164, 708 (1949).

IT is of interest to find that Drs. Kumagai and Isoda's results are in agreement with the earlier measurements at the National Gas Turbine Establishment. The constant $T / d_{0}{ }^{2}$ they refer to as the specific burning-time is the inverse of a quantity referred to in the work at the National Gas Turbine Establishment as the evaporation constant $\lambda$. In the case of liquid fuel drops, the latter concept is perhaps of more general significance, as it can be applied to evaporation under both non-burning and burning conditions. In the low-temperature case the evaporation-rate is determined by diffusion processes, and in the high-temperature case the evaporationrate is determined by heat transfer processes. In both cases experiments have shown that the mass evaporation-rate is proportional to the first power of the radius of the drop. Hence in both cases $T / d_{0}{ }^{2}$ is constant, and may be conveniently referred to in the general case as the specific lifetime of the drop.

Without further details, it would appear that the suggestion of Kumagai and Isoda that catalytic effects are of importance in the case of suspension on a platinum wire is unlikely. The investigations at the National Gas Turbine Establishment of the mechanism of the combustion of single drops of liquid fuel (in which all the combustion reactions occur in the vapour phase) have emphasized that the heat transfer to the drop is the dominant factor determin. ing its life. This being so, a platinum wire suspension (which presumably through geometric necessity would pass through the flame surrounding the drop) would increase the heat transfer of the drop, and hence would decrease its life as compared to the case of suspension on a silica filament.

\section{G. A. E. Godsave}

National Gas Turbine Establishment, Ministry of Supply. Nov. 7.

\section{Thermal Conductivity of Barium Strontium Oxide}

ONLY two values of the thermal conductivity of barium strontium oxide have been published : 0.00034 cal. deg. ${ }^{-1} \mathrm{~cm}^{-1}$ sec.-1 obtained by Clausing and Ludwig', and $0.000123-0.0013 \mathrm{cal}$. deg..$^{-1} \mathrm{~cm}^{-1}$ sec.-1 by Patai and Tomaschek ${ }^{2}$. Hamaker ${ }^{3}$ pointed out, however, that the methods employed by these workers were open to objections, since they depended on optical pyrometric mèsurements made on coated cathodes, and no allowance was made for the semitransparency of the coating.

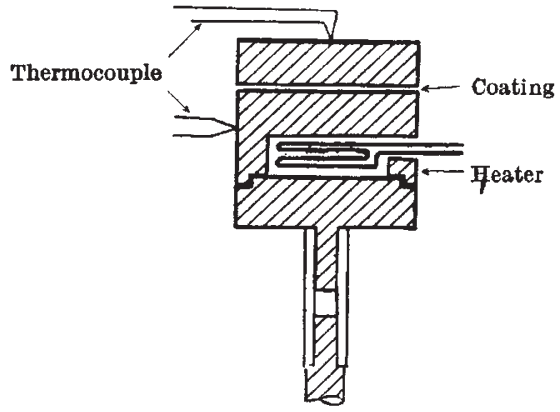

A method based on Lees's disk has been developed to overcome these objections. The assembly, shown in the accompanying diagram, consisted of three nickel disks, $l$ in. diameter and $\frac{1}{6}, \frac{1}{2}$, and $\frac{1}{4}$ in. wide respectively. The centre $\frac{1}{2}$-in. disk contained an alundum-covered, molybdenum-strip heater closed in by the lower disk. Barium strontium carbonate was sprayed on the top of the centre piece and the top disk pressed on to it. Thermocouples welded to the nickel were used for measuring the temperaturedrop across the coating, and leads permitted the passage of current through it for activation purposes. The whole block, supported on a ceramic tube, was erected in a continuously pumped demountable bulb, and the carbonate decomposed by heating the block to $950^{\circ} \mathrm{C}$. by a high-frequency coil. After cooling, the heater was switched on, and thermocouple read. ings taken when a steady state had been reached. Since coatings of the order $50-200 \mu$ were used, the 